\title{
The Flipped Classroom: Two Learning Modes that Foster Two Learning Outcomes
}

\author{
Eugenia M. W. Ng \\ Hang Seng Management College, Hong Kong SAR, China
}

\section{Eugeniang@hsmc.edu.hk}

\begin{abstract}
The study involved student teachers enrolled in early childhood teaching at a teacher training institute in Hong Kong Special Administrative Region. Seventy-four students participated in flipped classroom activities during their first semester of study. Students were told to learn from online videos related to using image editing software in their own time and pace prior to the next class. When they met in class, they were asked to apply their recently acquired editing knowledge to edit an image of their own choice related to the theme of their group project. At the end of the activity, students were asked to complete an online questionnaire. It was found that students had rated all five questions relating to generic skills highly, with self-study skills rated the highest. They particularly enjoyed the flexibility of learning on their own time and pace as a benefit of the flipped classroom. Data collected from students' project pages show they had used average of 3.22 editing features for the theme images for their project. Most groups had inserted text followed by using the filter function. It is possible that these two functions are more noticeable than other editing functions. In conclusion, students were able to apply their self-learnt knowledge in a real-life situation and they had also developed their generic skills via the flipped classroom pedagogy.
\end{abstract}

Keywords: flipped classroom, generic skills, online videos, photo editing, student teacher

\section{Introduction}

The traditional teacher-centered education system stems from the Industrial Age which emphasizes content instruction and regurgitation. This type of learning approach is inappropriate for today's learners: "digital natives" who have grown up with information technology (IT) (Prensky, 2005). It is also inadequate in preparing them for solving complex and ill-structured problems in a knowledge-based society (Macdonald \& Hursh, 2006). Indeed, the Curriculum Development Council in Hong Kong Special Administrative Region has proposed to reform the school curriculum so that school children do not just learn the subject contents, which are categorized into eight

Material published as part of this publication, either on-line or in print, is copyrighted by the Informing Science Institute. Permission to make digital or paper copy of part or all of these works for personal or classroom use is granted without fee provided that the copies are not made or distributed for profit or commercial advantage AND that copies 1) bear this notice in full and 2) give the full citation on the first page. It is permissible to abstract these works so long as credit is given. To copy in all other cases or to republish or to post on a server or to redistribute to lists requires specific permission and payment of a fee. Contact Publisher@InformingScience.org to request redistribution permission. key learning areas, but they also develop nine generic skills such as collaboration, critical thinking, IT, numeracy, problem solving, self-management and self-study so that they can tackle the challenges of the 21st century (Curriculum Development Institute, 2001). Similarly, all students are expected to be competent with seven generic intended learning outcomes when they graduate from the Hong Kong Institute of Education

Editor: Eli Cohen

Submitted: October 28, 2015; Revised: February 10, 2016; Accepted: March 1, 2016 
(HKIEd) where the author worked (Hong Kong Institute of Education, 2014). It has been found that students were able to develop some of their generic skills by engaging in online discussion (Ng, 2009).

The flipped classroom is a new pedagogical method consisting of online video lectures that learners watch in their own time and space so that they are responsible for their own learning prior to attending classes (O'Flaherty \& Phillips, 2015). In the classroom they participate in group activities, while the teacher provides support - particularly to those students with additional educational needs (Baepler, Wlaker, \& Driesson, 2014). This learning strategy is completely opposite to the traditional teaching approach, in which learners are expected to listen to teachers during class hours and complete activities outside of class. There are different names for the flipped classroom including "reverse instruction," "inverted classroom," and "24/7 classroom" (Bergmann \& Sams, 2012) but it is a subset of "blended learning" (Staker \& Horn, 2012). The flipped classroom employs a student-centered learning approach based on constructivism and zone of proximal development (ZPD) advocated by Vygotsky (1978). Constructivism emphasizes the need to understand learners' prior knowledge when educators are delivering new knowledge. However, the development of learners' full potential within the ZPD relies on social interaction such as peer interaction, scaffolding, and modelling (Vygotsky, 1978). The flipped classroom provides multiple avenues for fostering interactions between learners and digital materials and among learners in classes so that each learner's potential can be developed in full.

Baepler, Wlaker, and Driesson (2014) found that one class of university students participating in the flipped classroom approach performed better when compared with another class using the traditional learning approach, while another class performed similarly to the results of the traditional learning approach. On the other hand, Kong (2015) found that junior secondary school children developed greater critical thinking skills when using the flipped classroom strategy. Surveys of 17 studies related to flipped classroom practices found that there were mixed feelings about watching online videos instead of attending lectures and yet the participants were very positive about their in-class group activities (Bishop \& Verleger, 2013). Moreover, learners were much better prepared in class when they were given optional video lectures than when they were given a textbook to read). Given the inconsistent findings regarding the advantages of flipped classroom pedagogy and the importance of developing generic skills for students, this study aims to investigate whether the flipped classroom can foster students' generic skills, relating in particular to information technology, self-management, and self-study, in addition to acquiring the content knowledge. The following section discusses the research setting and findings. Finally, conclusions are drawn and future research directions are proposed.

\section{The Study}

\section{Participants}

The current study was conducted during the first semester of 2015 at the HKIEd, the only teacher education institute in Hong Kong even though some universities have education faculties. It involved student teachers (hereafter, students) enrolled in the Higher Diploma in Early Childhood Education during the first semester of their studies. Almost all the participants were female students who expected to teach in kindergartens (K1-K3). All the participants had recently completed their secondary school education. Two classes participated in the study: one class had 38 students, while the other had 36 students. 


\section{The Course}

The participants were taking an "Information Technology in Education" course taught by the author during the study period. This was a 3-credit course, which meant that the students attended weekly for 13 weeks; each session lasted 3 hours and normally consisted of lecture and hands-on practical sessions. The lessons were conducted in Cantonese. The participants were expected to learn some basic concepts about IT and its use in early childhood education and also developed some practical software skills using some popular free software. Students learnt the editing functions of Google wiki sites for the first two weeks of the course in order to be able to use it as a platform for their group project that aimed at consolidating students' content, pedagogy, and technology knowledge (Hughes, 2005; Koehler, Mishra, \& Yahya, 2007). Google wiki was chosen because all the students were provided with Gmail accounts by HKIEd. The group project counted for $50 \%$ of the total assessment, which was to design wiki pages for teaching any topic related to early childhood education in groups.

\section{Flipped Classroom}

At the end of lesson three, students were introduced to the flipped classroom pedagogy. They were required to learn about a web-based photo editing software called Pixlr in their own time prior to attending classes. There were a total of 19 video clips which were created by a research assistant supervised by the author. The short videos show various editing functions of Pixlr as shown in Figure 1. Students could view any video based on their own needs, and they were reminded that it was not necessary to watch them all. When the students attended classes the following week, they were asked to apply the learned techniques to editing at least one image related to their wiki project in a group.

\section{Screen shot}

\section{內容}

\section{1開呴Pixlr}

$\underline{\underline{2}}$ 註冊

$\underline{3}$ 登入

4語言設置

5打開㘣片

6 馔压丁具、捲目、粘貼

7 㢝㧼厂具、清除

8 㚗索丁具、诱明背意

9 保存PNG

10 圆片合併、彎控和戀形

11 福製圆層、圆層位置

12 更揬背意

13 㽷史記籍

14 保存JPG

15 㘣片格式

16 濾镜

17 調節像素

18 亮度、㡤比度

19色相、色彩玶衡、飽和度

\section{Translation}

Contents

1. Open Pixlr

2. Sign Up

3. Login

4. Select language

5. Select images

6. Select tools, copy and paste

7. Wand tool, clear

8. Marquee tool, transparent background

9. Save images in PNG format

10. Merge images, change images, and shapes

11. Create layers, move layers

12. Change background

13. Editing history

14. Save images in JPG format

15. Formats of images

16. Using filter

17. Adjust pixels

18. Adjust brightness, contrast

19. Adjust hue, color balance, and saturation

Figure 1: Online video clips 


\section{Data Collection}

At the end of the flipped classroom activities, students were asked to participate in an online questionnaire. The questionnaire was written in English and Chinese. The questionnaire captured responses by using a 5-point Likert-type scale ranging from 1 (strongly disagree) to 5 (strongly agree) regarding whether their generic skills and content knowledge had been developed by participating in the flipped classroom pedagogy. Completion of the questionnaire was voluntary and they were given one week to do this.

\section{Findings and Discussion}

A total of 55 questionnaires were returned, representing a return rate of $73.3 \%$. Table 1 shows that students highly regarded the flipped classroom activities. The mean scores for the five questions asked were very high (all greater than 2.5) and it ranged from 3.85 to 4.04 . The standard deviations for all 5 questions were very similar, ranging from 0.62 to 0.68 . It was very encouraging to know that they rated "I have developed self-study skills via flipped classroom activities" the highest, followed by "I have developed self-management skills." These are vital skills for studying and working in the $21^{\text {st }}$ century (Curriculum Development Institute, 2001; Hong Kong Institute of Education, 2014).

Table 1: Means and Standard Deviation of Generic Skills Developed

\begin{tabular}{lll}
\multicolumn{1}{c}{ Question } & Mean & S.D. \\
$\begin{array}{l}\text { Q3. I have developed self-study skills via flipped classroom } \\
\text { activities. }\end{array}$ & 4.04 & 0.67 \\
$\begin{array}{l}\text { Q2. I have developed self-management skills via flipped } \\
\text { classroom activities. }\end{array}$ & 3.98 & 0.62 \\
$\begin{array}{l}\text { Q5. I should be able to transfer the generic skills that I have } \\
\text { developed during the flipped classroom experience to } \\
\text { other courses and/or workplaces }\end{array}$ & 3.95 & 0.68 \\
$\begin{array}{l}\text { Q4. I have developed IT skills via flipped classroom activi- } \\
\text { ties }\end{array}$ & 3.89 & 0.66 \\
$\begin{array}{l}\text { Q1. I have fully understood the contents of the topic via } \\
\text { flipped classroom activities. }\end{array}$ & 3.85 & 0.65
\end{tabular}

Students could watch the videos multiple times and had watched the online videos 872 times in total. On average, each student watched 11.64 videos during the two weeks of flipped classroom activities. Since students could watch the online videos more than once, the total number of views for some videos was more than the number of participants ( 75 students), as shown in Table 2. These were: "formats of images", "wand tool, clear" and "adjust hue, color balance, and saturation." Conversely, the number of views was relatively low for simple operations such as "login," "select language," "editing history," and "save images in JPG format." However, it is interesting to note that an advanced editing feature "create layers, move layers" was viewed only 28 times whereas the "merge images, change images, and shapes" video was viewed 65 times. It was expected that some students might need to create layers to merge images but it is possible that they had learnt about layers previously or they did not know that using layers would be more convenient when merging and changing images. 
Table 2: Number of Videos Watched

\section{Video}

15. Formats of images

7. Wand tool, clear

19. Adjust hue, color balance, and saturation

8. Marquee tool, transparent background

10. Merge images, change images, and shapes

18. Adjust brightness, contrast

9. Save images in PNG format

1. Open Pixlr

6. Select tools, copy and paste

17. Adjust pixels

2. Sign up

12. Change background

5. Select images

11. Create layers, move layers

16. Using filter

3. Login

4. Select language

13. Editing history

14. Save images in JPG format

\section{Number of Views}

86

78

76

67

65

62

50

49

45

45

35

30

28

28

28

27

27

23

23

In addition to the five questions mentioned above, students were also asked to select multiple answers regarding their feelings about the flipped classroom experience. It was found that the answers could be grouped into three categories: strong feelings, moderate feelings, and least strong feelings. Most students felt more strongly about the domains "learn in my own time" and "learn at my own pace" than other items; this concurs with the earlier findings of developing self-study skills via the flipped classroom activities (DeGrazia, Falconer, Nicodemus, \& Medlin, 2012; O'Flaherty \& Phillips, 2015). It was most encouraging to know that very few students had negative feelings such as "feel helpless," "less motivated to learn," and "difficult to learn" when participating in flipped classroom activities. These three items were intended to counter-check students' responses. 
Table 3: Feelings about the flipped classroom

Please choose how you feel about the flipped classroom experience. (multiple answers)

Percentage

F. Learn on my own time

64.80

E. Learn at my own pace

57.40

B. Cater for individual differences

38.90

A. Chances for collaboration

37.00

G. Learning is more interesting

C. Difficult to learn

H. Less motivated to learn

5.60

D. Feel helpless

3.70

Students' wiki group project pages were examined after the flipped classroom activities. It was found that each group had used an average of 3.22 editing functions and the standard deviation was 1.64. However, some groups had stated which techniques to use when merging photos, while some groups did not do so. Therefore, the three groups that merged photos together were regarded as having used the "merge" function without counting other functions that they might have used. Each group of students on average used 2.76 functions and it ranged from using one to six editing functions. Table 4 shows five groups used only one editing function, while one group used six editing functions and two groups used five editing functions.

Table 4: Editing functions used for each group

\begin{tabular}{ccl}
$\begin{array}{c}\text { Group } \\
\text { No. }\end{array}$ & $\begin{array}{c}\text { \# of Func- } \\
\text { tion Used }\end{array}$ & \multicolumn{1}{c}{$\begin{array}{l}\text { Function } \\
1\end{array}$} \\
2 & 4 & hue, saturation, color balance, text \\
3 & 1 & text \\
4 & 1 & text \\
5 & 1 & color balance \\
6 & 5 & hue, filter (emboss), saturation, brightness, text \\
7 & 1 & text \\
8 & 3 & adjust hue, filter (water swirl), filter (pointinize) \\
9 & 2 & merging images, text \\
10 & 6 & text, filter (emboss), contrast, saturation, color balance, \\
11 & 2 & brightness \\
12 & 3 & merge images, filter (engrave) \\
13 & 1 & merging images \\
14 & 5 & filter (scanliness), text, filter (kaleidoscope), color bal- \\
15 & 2 & ance, filter (emboss) \\
16 & 3 & hue, saturation \\
17 & 4 & text, filter (halftone), filter (kaleidoscope) \\
& 3 & frightness, contrast, marquee tool, merge images \\
& &
\end{tabular}


Table 5 shows that a total of 47 functions had been used. Most groups inserted text into the images, followed by the number of groups using the filter function. Since there are many filter functions, they are grouped into filter function only. It is possible that these two editing functions have the most noticeable effect.

Table 5: Summary of editing functions used

\begin{tabular}{lc}
\multicolumn{1}{c}{ Function } & No. \\
Text & 10 \\
Filter & 12 \\
Hue & 5 \\
Saturation & 4 \\
Color balance & 4 \\
Brightness & 3 \\
Merge images & 4 \\
Contrast & 2 \\
Get rid of background & 1 \\
Marquee tool & 1 \\
Total & 47
\end{tabular}

However, a number of steps are usually required prior to merging a photo, such as getting rid of the background and re-sizing different images. Figure 2 shows an example of merged photos. Students stated that they had used the "brightness," "contrast," "wand tool," and "merging images" techniques when merging the photos, but all of these techniques were grouped together into the single domain "merging images". On the other hand, Figure 3 shows another example of merged photos. Students stated that they had added "text" when merging the photos.

Original image

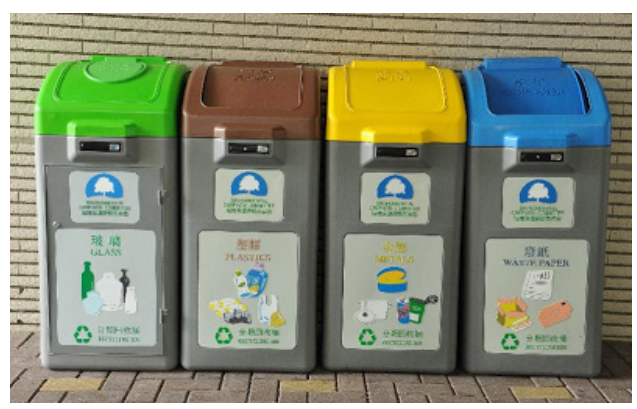

\section{Edited image}

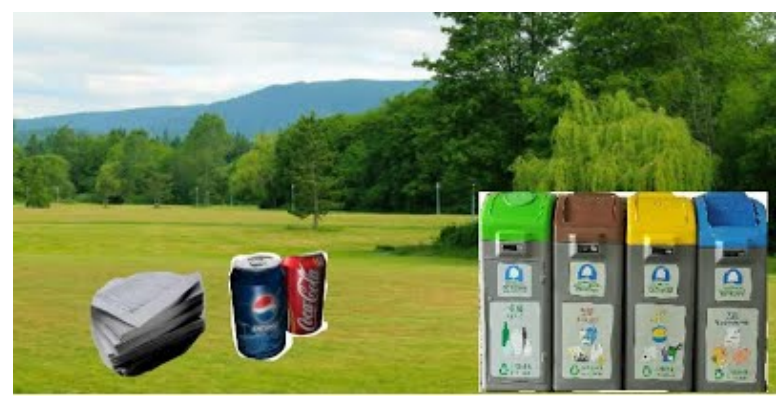

Figure 2: Example of an edited photo 
Original images

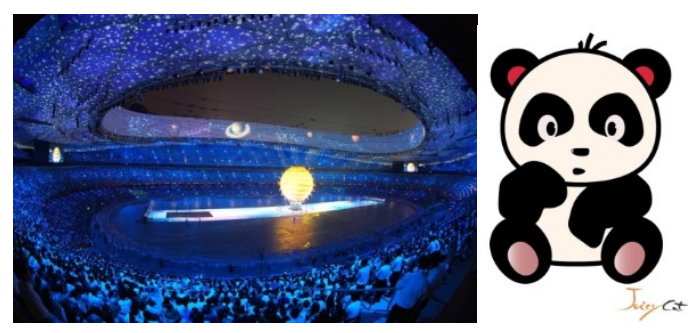

Edited image

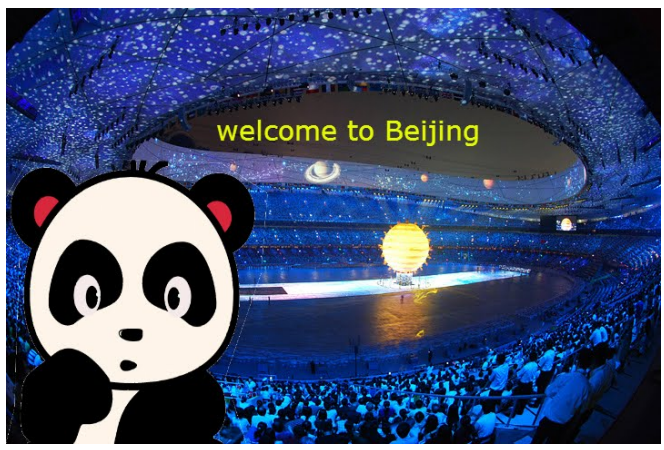

Figure 3: Example of another edited photo

\section{Conclusions and Future Direction}

This study provides some concrete examples and evidences on flipped classroom and students' learning outcomes. Data were collected from questionnaires and student projects. It was found that students had rated all five questions highly, with self-study skills rated the highest. They enjoyed the flexibility of learning on their own time and pace the most. Data collected from student projects demonstrates that that they had used an average of 3.22 editing features for the theme images for their wiki projects. Inserting text, using the filter and hue functions were the most popular. However, there are some limitations to this study. First, the responses of students in the questionnaire were based on their subjective perceptions. Second, the findings were based on their self-reporting of the editing features that they used. Third, the findings of the studies were confined to the context of the research.

Future research directions may include 1) asking students to participate in a focus group meeting to elaborate on their opinions of the flipped classroom strategies, 2) asking students to edit an image on their own so that it would be easier to observe whether individual students had learnt the contents well, 3) giving students pre- and post-activity tests related to the video contents, to gain an objective examination of the flipped classroom activities, and 4) comparing the findings of two classes, one class using the flipped classroom pedagogy (treatment) with another class using the traditional learning and teaching methods (O'Flaherty \& Phillips, 2015). In conclusion, flipped classroom pedagogy could foster two learning outcomes for students: generic skills and content knowledge.

\section{Acknowledgements}

The author is very thankful to students for participating and allowing her to cite their work and responses. Special thanks go to Pecco Yin for his good research support.

\section{References}

Baepler, P., Walker, J. D., \& Driessen, M. (2014). It's not about seat time: Blending, flipping, and efficiency in active learning classrooms. Computers and Education, 78, 227-236.

Bergmann, J., \& Sams, A. (2012). Flip your classroom: Reach every student in every class every day. Washington, DC: International Society for Technology in Education.

Bishop, J. L., \& Verleger, M. A. (2013). The flipped classroom: A survey of research. $120^{\text {th }}$ ASEE Annual Conference \& Exposition, Atlanta. 
Curriculum Development Institute (2001). Learning to learn - The way forward. Retrieved 29 Jan 2016 from http://www.edb.gov.hk/en/curriculum-development/cs-curriculum-doc-report/wf-incur/index.html

DeGrazia, J. L., Falconer, J. L., Nicodemus, G., \& Medlin, W. (2012, June). Incorporating screencasts into chemical engineering courses. In Proceedings of the ASEE Annual Conference \& Exposition, 2012.

Hong Kong Institute of Education. (2014, September) Graduate Intended Learning outcomes. Retrieved from https://www.ied.edu.hk/lt/view.php?m=3792\&secid=3805

Hughes, J. E. (2005). The role of teacher knowledge and learning experiences in forming technologyintegrated pedagogy. Journal of Technology and Teacher Education, 13(2), 377-402.

Koehler, M. J., Mishra, P., \& Yahya, K. (2007). Tracing the development of teacher knowledge in a design seminar: Integrating content, pedagogy, \& technology. Computers and Education, 49(3), 740-762.

Kong, S. C. (2015). An experience of a three-year study on the development of critical thinking skills in flipped secondary classrooms with pedagogical and technological support. Computers and Education, 89, 16-31.

Macdonald, G., \& Hursh, D. (2006). Twenty-first century schools: Knowledge, networks and new economies. Rotterdam, The Netherlands: Sense Publication.

Ng, E. M. W. (2009). Development of student teachers' generic skills through computer-supported learning environment. International Journal of Instructional Media, 36(4), 427-437.

O'Flaherty, J., \& Phillips, C. (2015). The use of flipped classrooms in higher education: A scoping review. Internet \& Higher Education, 25, 85-95.

Prensky, M. (2005). Listen to the natives. Educational Leadership, 63(4), 8-13.

Staker, H., \& Horn, M. (2012). Classifying K-12 blended learning. Retrieved from the Innosight Institute website at http://files.eric.ed.gov/fulltext/ED535180.pdf

Vygotsky, L. S. (1978). Mind and society: The development of higher mental processes. Cambridge, MA: Harvard University Press.

\section{Biography}

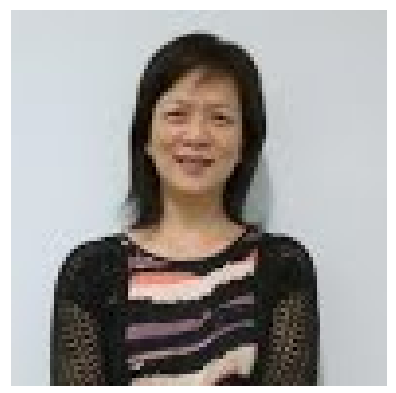

Eugenia M. W. Ng works as College Registrar and Adjunct Professor at the Department of Computing at the Hang Seng Management College (HSMC). She has been a teacher educator for twenty years prior to joining HSMC in 2016. She has been a research investigator of various internal and external funded projects. She has had over one hundred articles published in conference proceedings, journals, newspapers and as book chapters. Her publications have appeared in many reputable international journals such as Australasian Journal of Information Technology, Computers \& Education, Issues in Informing Science and Information Technology, Internet and Higher Education. She was the editor and coeditor for a number of referred books and journals. 